\title{
BRASIL: A ECONOMIA DO CAPITALISMO SELVAGEM*
}

\author{
REGIS DE CASTRO ANDRADE
}

\begin{abstract}
Metaforicamente, o Brasil é uma das fronteiras do mundo capitalista. É uma terra de ninguém a ser conquistada pelas armas e transformada num negócio rentável. De um ponto de vista mais analítico, é um país de industrialização recente onde o capital se espraiou cegamente sem desenvolver concomitantemente a consciência de si, ou as instituições que poderiam ter atenuado os seus efeitos sociais inaceitáveis.

Qualquer que seja o ponto de vista, trata-se de uma experiência de capitalismo selvagem. Resta saber se a experiência é um sucesso. Do ponto de vista do crescimento, a resposta é sim. O PNB cresceu a uma taxa geométrica média de 7\% de 1947 a 1977. Do ponto de vista do bem-estar da população a resposta é obviamente não. A " metade não privilegiada " da população nunca foi tão desprivilegiada, nem tão numerosa. A maioria dos empregados em trabalhos relativamente estáveis ganha hoje menos (em termos reais) do que ganhava há vinte anos atrás.

Crescimento econômico acelerado e pobreza persistente - eis uma das características contraditórias do caso brasileiro. É interessante observar que, nas últimas décadas, o Brasil é um exemplo raro de transição bem sucedida para a modernidade capitalista. Como foi possível isso no ambiente internacional hostil do século vinte?
\end{abstract}

\footnotetext{
* Originalmente publicado em Revista de Cultura e Política, n ${ }^{4}$, 1981. Em nota, o autor esclarecia que se dirigia ao "público estrangeiro" e que o artigo é "uma síntese das informações e interpretações básicas acerca da economia brasileira recente, que ajuda a entender a importância crucial da política econômica para as alternativas da conjuntura atual no país".
} 
Este artigo pretende fornecer elementos para a discussão dessas questões gerais. Entretanto, as condições sócio - políticas específicas e as condições históricas gerais do desenvolvimento não são aqui diretamente abordadas. Ao invés de utilizar o caso brasileiro como ilustração de uma teoria geral, o trabalho focaliza as estruturas e mecanismos específicos da acumulação capitalista no país.

A acumulação capitalista é, ao mesmo tempo, um sistema dinâmico de relações quantificáveis e o cenário histórico de ações humanas deliberadas. Essa antítese deve ser reconciliada de alguma maneira, se pretender uma análise significativa. A premissa deste trabalho é de que os mecanismos de acumulação impõem-se sobre os homens. Não quer isso dizer que o agir humano seja uma futilidade; os processos econômicos impõem-se sobre os homens modulando e dirigindo as suas ações. A qualquer momento do processo histórico, a política é decisiva; mas a política não pode furtar-se às restrições impostas pela economia.

A primeira parte deste artigo é uma introdução descritiva às origens da economia brasileira moderna, desde os anos 30 até a crise econômica de 1962-1967. A seção seguinte analisa o "modelo brasileiro". A parte três aborda o boom econômico de 1968-1973 (o "milagre brasileiro") e sua evolução recente. A última tece algumas considerações sobre as perspectivas da economia brasileira à luz das análises prévias.

\section{BREVE INTRODUÇÃO HISTÓRICA}

Com o colapso do mercado internacional do café em 1930 começa no Brasil a era industrial. A repentina contração do comércio exterior que se seguiu ao crack de 1929 foi parcialmente controlada pela compra dos estoques cafeeiros pelo Governo. Essa política, e as condições favoráveis criadas pelas dificuldades de importação, estimularam investimentos industriais e sustentaram a economia durante os anos críticos. $\mathrm{O}$ produto total caiu menos de $10 \%$ nos anos iniciais da depressão, e por volta de 1933 restabelecia os níveis de 1929. Essa combinação de restrições externas e políticas econômicas internas favoráveis reforçaram os fatores internos de desenvolvimento. A indústria assume gradualmente o papel de líder desse processo. $\mathrm{O}$ mercado interno torna-se mais atraente do que o mercado externo (Furtado, 1968).

A revolução de 30, liderada por Getúlio Vargas, fortaleceu a União em detrimento dos sistemas locais de poder. Esse fator por si só se- 
dimentaria as bases do desenvolvimento industrial, já que reduzia a influência dos velhos políticos ligados aos interesses exportadores. Mas a indústria não seria diretamente estimulada até meados dos anos 30 .

Em 1937, num contexto político de forte movimento popular, Vargas assume poderes ditatoriais plenos. As tendências autoritárias e centralizadoras prévias transformam-se em fortes estruturas político-administrativas. A aliança jamais desfeita entre a burguesia urbana e a oligarquia rural é então consolidada. As oligarquias locais são removidas das esferas centrais do Governo, em troca da paz social e da manutenção de seu poder político e econômico local. A burguesia industrial emerge como a classe mais influente no Governo.

No Brasil, a burguesia industrial ascendeu num período de crise. A base material da dominação oligárquica fora enfraquecida pela crise mundial, mas os velhos políticos ainda controlavam as alavancas do país. Nesse contexto, a burguesia ascendente somente poderia consolidar sua supremacia sobre a oligarquia por um lado, e sobre os movimentos populares por outro, assumindo o controle de um Estado forte (Andrade, 1978).

O controle dos processos econômicos pelo Executivo é uma característica central da ordem capitalista no país. Durante o Estado Novo, várias agências econômicas estatais foram criadas com o poder de formular e implementar políticas setoriais. A nova Constituição democrática de 1946 não alterou essa estrutura administrativa.

O começo do desenvolvimento industrial no Brasil foi favorecido pela crise das economias industrializadas nos anos 30 e durante o período da Segunda Guerra. A partir de 1945 a competição internacional aumenta. Em 1947 foi estabelecido forte controle cambial com taxas de câmbio múltiplas. Os ingressos do café, inflados pelos preços internacionais ascendentes, foram parcialmente apropriados pelo Estado e transferidos para a indústria. Taxas de câmbio de bens de capital e de bens intermediários subsidiadas, por um lado, e câmbio para bens de consumo artificialmente elevado, por outro, geraram um mercado protegido para os segundos. Esse sistema desencorajou a integração vertical da indústria como um todo.

O Plano de Metas (1956-1961) do presidente Juscelino Kubitschek foi uma tentativa de corrigir o desequilíbrio industrial anteriormente descrito (Lessa, 1964). Esse período constituiu-se num período de reorientação na história econômica do Brasil. Mudanças substanciais foram introduzidas na abrangência e magnitude da intervenção estatal, na estrutura industrial e no modelo de relações com os países industrializados. Os investimentos públicos saltaram de $25.8 \%$, em média, do total de investi- 
mentos em 1952-1956 para 35.6\% em 1956-1960, em virtude sobretudo de investimentos estatais em programas de energia elétrica e infra-estrutura de transportes (EPEA, 1966). Os vultosos recursos financeiros necessários para o desenvolvimento acelerado foram obtidos através de instrumentos fiscais e monetários, incluindo emissão de moeda. Um elenco de instituições de desenvolvimento foi mobilizado ou criado para lidar com questões de desenvolvimento setorial, tarifas e questões monetárias e financeiras.

Os Grupos Executivos, para citar apenas um exemplo, tinham por atribuição a definição das estratégias e padrões para o desenvolvimento dos principais setores industriais, bem como recomendar ou mesmo aprovar incentivos para projetos de investimento específico (Martins, 1976). Essa poderosa máquina institucional operava preponderantemente à margem dos controles democráticos, abrigando os interesses do big business industrial, tanto nacional quanto estrangeiro.

Já em 1953 eram tomadas medidas extremamente favoráveis ao capital estrangeiro. Essa política foi reforçada por Kubitschek, envolvendo taxas de câmbio preferenciais para remessas de lucros, legislação favorável para registro de capital, direito de importação de bens de capital sem cobertura cambial pelas autoridades e reduções ou isenções tarifárias. Outras vantagens de crédito e tributação completavam o quadro de incentivos, que tornavam as condições de investimento extremamente atraentes para investidores externos. Em termos quantitativos os resultados foram substanciais, conforme demonstra a tabela 1 .

Tabela 1: Entradas e saídas de Capital Estrangeiro 1947 - 1961 (em milhões de dólares)

\begin{tabular}{lcc}
\hline Fluxos de Capital & $1947-1955$ & $1956-1961$ \\
\hline Ingressos - Média Anual & 265.3 & 707.8 \\
Financiamentos & 204.0 & 561.8 \\
Investimentos diretos & 61.3 & 146.0 \\
\hline Saídas - Média Anual & 203.7 & 489.5 \\
Amortizações & 85.3 & 340.5 \\
Lucros e outros & 118.4 & 149.0 \\
\hline Saldo Anual Médio & 61.6 & 218.3 \\
\hline
\end{tabular}

Fonte: Balança de Pagamentos do Brasil

Boletins do SUMOC e Banco Central

(1) Empréstimos compensatórios não incluídos 
Os investimentos estrangeiros diretos concentraram-se em grandes empreendimentos industriais, especialmente nos seguintes setores: indústria automobilística, estaleiros, mecânica pesada, e siderúrgicas.

O grau de monopólio na indústria brasileira foi reforçado pelos investimentos estrangeiros diretos. Todos os novos setores dinâmicos apresentavam uma estrutura oligopólica. Grandes empresas de montagem defrontavam-se à rede de fornecedores em situação de oligopsônio. Conseqüentemente os ganhos de produtividade gerados em qualquer ponto, praticamente, na cadeia econômica, tendiam a ser transferidos através de mecanismos de preço, ou para as indústrias terminais ou para as indústrias de bens de capital. Esse fenômeno poderia ter diminuído o dinamismo dos grandes investimentos. Entretanto as complementaridades internas, para a frente e para trás desses investimentos, no contexto de uma economia previamente em expansão, potencializaram seus efeitos desenvolvimentistas globais durante os primeiros anos do ciclo.

A médio prazo era previsível um excesso de acumulação. A estrutura altamente oligopolista da indústria implicava que taxas decrescentes de crescimento industrial afetariam gravemente unidades menores, fenômeno este que levaria, por sua vez, a uma maior concentração industrial. Problemas sérios de instabilidade dinâmica eram portanto inerentes a esse modelo de desenvolvimento. Ao mesmo tempo surgiram também problemas de realização dos lucros. A possibilidade de efetuar lucros, por mais reduzido que fossem, numa situação de excesso de capacidade poderia levar a remessas de lucros crescentes em períodos de baixa atividade, com efeitos negativos no balanço de pagamentos (Tavares, 1977).

Estritamente falando, o bloco de investimentos estrangeiros no fim dos anos 50 não desnacionalizou a indústria brasileira, posto que esses investimentos inauguraram novas linhas de produção. Pela mesma razão o crescente grau de monopólio não implicou, no começo, o desaparecimento de indústrias menores. Todos beneficiaram-se desse agrupamento (bunching) de investimentos com forte componente de capital estrangeiro. Os salários cresceram até 1959 , embora em proporção menor que a produtividade. $\mathrm{O}$ mercado de trabalho industrial também se expandiu significativamente, sobretudo na área urbana.

Essas são algumas das razões pelas quais tal estratégia de desenvolvimento não provocou reações imediatas por parte dos movimentos populares nacionalistas. Forte oposição nacionalista ocorreria no princípio dos 60, sob o Presidente João Goulart.

Durante esse período, a concentração de renda não foi acompa- 
nhada de redução absoluta da renda real de qualquer segmento da população trabalhadora urbana. Essa concentração era o produto natural (a) de um novo modelo de industrialização num contexto de oferta abundante de força de trabalho e, (b) de uma expansão muito rápida da demanda da força de trabalho de white collars tanto nos setores privados quanto públicos (Oliveira,1977).

A crise começou em 1962-1963. A capacidade de utilização estimada na indústria de bens de capital alcançou $60 \%$ no início dos 60 . (Reischstul e Goldenstein,1980). No setor da indústria pesada, a relação entre a demanda estimada e a capacidade era abaixo dos $30 \%$ nas caldeiras, turbinas elétricas, transformadores, estruturas metálicas e fornalhas horizontais. (CEPAL, 1963). O aumento da produção no setor de bens de capital como um todo caiu de $20 \%$ em 1962 para $2.6 \%$ em 1963 e diminuiu nos anos subseqüentes (Leff, 1968).

Discute-se se a crise poderia ter sido atenuada por maiores esforços de investimentos por parte do Estado. Os recursos financeiros eram entretanto particularmente escassos. Os déficits orçamentários já tinham alcançado a elevada taxa de $4.2 \%$ do PNB em 1963. O crédito externo, necessário em grande escala em virtude dos elevados coeficientes de importação dos investimentos estatais, também não era suficiente. Isso se devia à má vontade ou ceticismo das agências internacionais durante esses anos de inflação alta, de política nacionalista e de agitação política geral no país (Belluzzo e Cardoso de Mello, 1977).

$\mathrm{Na}$ indústria de bens de consumo duráveis, os efeitos da diferenciação de produtos e os esforços de promoção de vendas poderiam ter sido potencializados pela decisão do Governo de expandir o crédito ao consumidor. Esse mecanismo foi tentado de maneira tímida, com resultados modestos naqueles anos de recessão. A taxa média de crescimento setorial caiu de 24\% em 1955-1962 para 4.1\% em 1962-1967.

Os déficits orçamentários, parcialmente devidos à precariedade do sistema financeiro existente, aceleraram o processo inflacionário até quase 100\% em 1963-1964 a despeito da diminuição dos salários (Kalil,1973). Por trás desse processo estava a decisão política, por parte do governo nacionalista do presidente Goulart, de não desistir das políticas do desenvolvimento. Portanto, deve-se levar em conta fatores estruturais e conjunturais de ordem econômica e política nas tentativas de explicação da crise de 1962-1967 no Brasil.

Estabeleceu-se um regime autoritário no qual o Congresso e os sindicatos praticamente não atuavam. Entretanto, esse regime não era uma mera ditadura militar. Esse novo regime expressava o crescente poder 
político, ao nível do Executivo, da grande burguesia industrial associada aos altos escalões da tecnocracia estatal e da alta oficialidade militar.

A meta número um do governo era reduzir a inflação. Apesar da severidade do programa de estabilização - especialmente no que tange à política salarial - os resultados não foram imediatos nem satisfatórios. A produção caiu mas os preços não foram afetados na mesma proporção. A habilidade por parte dos setores oligopolistas, em transferir todos os aumentos de custos para o preço final, foi uma das principais causas da ineficácia da terapia anti-inflacionária ortodoxa (Fishlow, A., 1972).

\section{O MODELO BRASILEIRO}

\section{A autonomia do "modelo"}

O desenvolvimento do capitalismo industrial no Brasil não pode ser dissociado do desenvolvimento do mundo capitalista. Mas seria ingenuidade pensar que a economia brasileira nada mais é do que o representante local de um sistema global único e que, por isso, conhecendo-se as leis do capitalismo internacional, se conhece as leis do capitalismo no Brasil. Evidências históricas específicas, um resumo das quais foi apresentado na primeira parte, demonstram que no Brasil foi necessária a prévia consolidação do Estado para que a rápida industrialização, incorporando capital estrangeiro, pudesse realizar-se.

Em outras palavras, foi necessário que a organização política das aspirações e forças sociais locais e das condições e potencialidades econômicas específicas, sob a liderança da burguesia, fornecessem o quadro institucional e as motivações para o desenvolvimento. Qualquer que seja a influência dos poderes externos na sua constituição, o Estado nacional expressa a identidade histórica específica de um país.

O desenvolvimento é no Brasil um processo ambivalente. Ele não eliminou o elemento de dominação inerente às relações centro-periferia; ele apenas modificou suas formas e modos de operação. Mas à medida que o desenvolvimento pressupunha a constituição de um sistema local de poder, lutando no plano internacional para o controle de uma riqueza interna crescente, ele trouxe à baila a questão nacional. Para uns, essa questão exprimiu-se em sonhos de futura Grande Potência. Outros preocuparam-se com a subordinação dos esforços produtivos nacionais 
aos interesses multinacionais.

Ao longo de algumas décadas, gerou-se no Brasil um sistema econômico relativamente autônomo. Sua economia diversificou-se e é, em grande parte, autodeterminada, no sentido de que suas flutuações cíclicas são principalmente explicadas por variáveis endógenas. Mesmo as poderosas tentativas das multinacionais $(\mathrm{MN})$ de adquirir completo domínio da economia são internas ao processo de decisão política brasileiro. Isso é claramente demonstrado por alguns estudos de caso descrevendo as negociações entre o governo, as $\mathrm{MN}$ e o capital nacional a respeito de grandes projetos envolvendo decisões estratégicas sobre tecnologia e alocação de recursos (Tavares, J. e Dick, V. M., 1974).

Já no início de 70 a natureza endógena do ciclo foi ressaltada (Singer, P., 1972). Mais recentemente, prestou-se mais atenção aos desequilíbrios setoriais da estrutura industrial, característicos dos países de capitalismo recente. Mais especificamente, essa instabilidade é explicada pela dimensão relativamente pequena das indústrias de bens de capital e bens duráveis. Essas indústrias se caracterizam por altas taxas de crescimento em períodos de expansão geral, seguidas por recessões graves. Nessa ótica, desequilíbrios externos e inflação não são fatores primários das crises. Eles são apenas sintomas de taxas decrescentes de expansão. Quando o ritmo da atividade econômica se desacelera, a luta pela massa decrescente de lucros inflaciona os preços. Recursos não investidos são transferidos ao circuito financeiro. $\mathrm{O}$ crédito estrangeiro necessário ao equilíbrio externo torna-se caro (Tavares, M. C. e Belluzzo, L. G. M., 1979).

Essa visão nega a validade tanto da teoria do sub-consumo quanto da sub-poupança, que gozavam de alguma credibilidade na década de 60. De acordo com a primeira, a distribuição desigual de renda induziria fortes investimentos de capital, diminuiria a proporção dos salários no valor adicionado, reforçaria a concentração de capital e finalmente levaria à estagnação, à medida que a demanda contida de bens duráveis fosse satisfeita. $\mathrm{O}$ argumento da "insuficiência de poupança" tem sido associado na América Latina à análise da relação capital-produto. Tem-se argumentado que escalas crescentes de produção associadas à substituição de importações envolvem demandas crescentes de capital. Rapidamente chega-se a um ponto no qual tais demandas são incompatíveis com a extensão do mercado. Ambas teorias foram discutidas por Fishlow (1974); a segunda teoria mencionada foi criticada por Tavares e Serra (1972). Para os propósitos desse trabalho, é suficiente mencionar que as taxas de crescimento obser- 
vadas no período 1968-1973 desautorizam a teoria da estagnação em qualquer de suas versões.

\section{O papel do Estado na economia}

A atividade econômica do Estado procura atingir ao mesmo tempo objetivos de dinamização e estabilização na economia como um todo. A participação estatal no total dos investimentos fixos é substancial, crescendo $38 \%$ em 1970 para $43 \%$ em 1978. Estima-se que $35 \%$ da demanda total de bens de capital produzidos localmente em 1975 foi gerada por investimentos públicos (Suzigan, W., 1976). Em 1974, o Estado controlava $68.5 \%$ das ações na mineração, $72 \%$ na siderúrgica, $96.4 \%$ na produção de petróleo e $34.8 \%$ na química e petroquímica. O Estado monopoliza o transporte ferroviário, o serviço de telecomunicações, geração e distribuição da energia elétrica e nuclear e outros serviços públicos. Todas essas atividades produtivas têm sido sustentadas pela estrutura financeira não-ortodoxa do Estado. Além de recursos orçamentários, o Estado estimula poupança privada a longo prazo através de benefícios tributários e creditados. O Estado também recolhe poupança forçada para os fundos sociais controlados pelo Governo e manipula enorme quantidade de recursos através do open market, que se mantém ativo pelas altas taxas de correção monetária e juros.

A atividade produtiva do Estado afeta o setor industrial como um todo de quatro maneiras diferentes. Primeiramente, ele gera economias externas que são apropriadas pelo setor privado. Uma pesquisa de 1977, sobre uma amostra de 1261 importantes empresas nos mais variados setores, revelou que os setores produtivos estatais contribuíram com $70 \%$ da produção industrial total; as escalas de produção e a intensidade de capital eram mais elevadas no setor público do que no setor privado, mas os lucros no setor produtivo estatal foram bem menores que a média, devido à sua política de preços baixos (Tavares, M. C. e Façanha, I. C., 1977). Em segundo lugar, o Estado atenuou as oscilações do setor de bens de capital através da manutenção da demanda durante os anos de dificuldades. Em terceiro lugar, o Estado teve papel decisivo no emprego e na demanda de bens de consumo, através do seu controle sobre as indústrias de construção. Grandes obras públicas e programas de habitação realizados pelo Estado são instrumentos estratégicos das políticas estabilizadoras do Governo. Em quarto lugar, as transações financeiras estatais remuneram o setor privado e ajudam a manutenção 
dos retornos privados globais nos anos de crise.

A concentração de renda, o Estado e a industrialização

Conforme foi mencionado antes, a industrialização rápida no contexto brasileiro levou naturalmente à concentração da renda. De 1964 em diante tal tendência foi reforçada por políticas do Governo.

Os salários básicos reais foram fortemente deprimidos. O salário mínimo oficial caiu uniformemente, em termos reais, do índice $100 \mathrm{em}$ 1960 para 52 em 1979 (DIEESE, 1979). Cerca de 60\% da força de trabalho assalariada foi diretamente atingida. Os salários médios reais permaneceram constantes de 1963 a 1970 (Wells, 1975); aumentaram um pouco durante o boom e parecem ter decrescido nos últimos anos. De qualquer forma, os salários não incorporaram os enormes ganhos de produtividade gerados nos últimos anos.

A crescente massa de mais valia - ou lucros totais - foi redistribuída segundo linhas determinadas pelas condições de mercado e pelas políticas governamentais beneficiando os estratos de alta renda. Dessa forma, a concentração de renda foi agravada pela escassez de certos profissionais altamente qualificados e pela capacidade quase ilimitada do Governo de comprimir os salários básicos; pelos esforços do Governo em assegurar a lealdade da burocracia pública, das Forças Armadas e dos serviços de segurança, e pela extensa corrupção; pela concentração de capital e propriedade bem como pela exacerbação de uma "ética da selva" nas classes dirigentes, empresariais e na classe média alta.

A história da expansão industrial brasileira é a história de uma

Tabela 2: Distribuição de renda pessoal 1960 - 1970 - 1976

\begin{tabular}{l|ccc}
\hline Estrato da população & \multicolumn{3}{|c}{ Proporção da renda total (\%) } \\
Economicamente ativa (a) & 1960 & 1970 & 1976 \\
\hline Baixa (50\%) & 17.71 & 13.91 & 11.8 \\
Média baixa (30\%) & 27.92 & 22.85 & 21.2 \\
Média alta (15\%) & 26.66 & 27.38 & 28.0 \\
Alta (5\%) & 27.69 & 34.86 & 39.0 \\
\hline TOTAL (100\%) & 100.00 & 100.00 & 100.0 \\
\hline Coeficiente de Gini & 0.50 & 0.56 & 0.60 \\
\hline
\end{tabular}

Fonte: Reichstul, H. P. e Goldenstein, L. 1980.

Dados para 1960 e 1970 baseados no Censo Demográfico.

Dado de 1976 da Pesquisa Nacional de Amostra por Domicílio.

Notas: (a) Idade da população 10-65 anos. 
série de descontinuidades econômicas. As "leis do mercado" têm sido constantemente desrespeitadas. Controles administrativos do câmbio, altos subsídios e crédito a taxas de juros negativas, períodos de deliberados desequilíbrios monetários e financeiros, controle salarial estrito: esses são alguns dos instrumentos criados para remover as barreiras à acumulação, contra a sabedoria do mercado e os conselhos dos economistas ortodoxos. Mas esse processo espontaneamente arbitrário está subordinado a outro tipo de lógica. A industrialização não foi o produto fortuito de um processo irracional. Essa lógica diferente pode ser percebida na peculiar mecânica de equilíbrio na industrialização brasileira.

No modelo brasileiro, o princípio da equalização da demanda agregada corrente à produção corrente não tem o papel de prima dona absoluta. Ele foi suplantado pelo princípio da equalização dinâmica da capacidade produtiva real à demanda rapidamente crescente. (Tavares, M. C., 1977). A capacidade produtiva real é determinada em grande parte pelos custos financeiros e tecnológicos, independentemente da demanda corrente. Por exemplo, a capacidade de inovação tecnológica a custo marginal praticamente nulo (importação de equipamento usado) e a disponibilidade de capital de giro a juros negativos foram os principais responsáveis pelos investimentos iniciais nos setores modernos. Incentivos fiscais também foram um fator importante nas decisões de investir. Previsões de consumo, por outro lado, não partem da premissa da estabilidade das condições correntes. A probabilidade de mudanças de parâmetros estruturais da economia a curto e médio prazo são também levadas em conta.

Níveis tão elevados de ociosidade como os que têm sido observados nos setores de ponta no Brasil teriam sido catastróficos em economias maduras, de crescimento lento. Aqui, excesso de capacidade é reabsorvido a médio prazo por forças dinâmicas operando na economia. Primeiramente, taxas positivas de crescimento (mesmo durante crises), acompanhadas por rápida concentração de renda, abrem perspectivas suficientemente favoráveis para as indústrias de bens duráveis, de modo a justificar grandes investimentos, mesmo se a demanda corrente for insuficiente. Em segundo lugar, a valorização de recursos de crédito e/ou a criação de novos instrumentos de crédito, num mercado financeiro sob o impacto das intervenções do Governo, pode causar uma repentina expansão do mercado nos setores "estratégicos" ameaçados. Em terceiro lugar, os investimentos estatais operam como uma variável relativamente independente no mercado de bens de capital. É verdade que o gasto de capital do governo não é contínuo em relação às indústrias individuais. Setores 
distintos são ativados em momentos diversos. Mas o impacto global dos investimentos estatais é muito grande e permanente. Esses investimentos não são apenas medidas paliativas, empregadas neste ou naquele momento. Eles são componentes essenciais do complexo mecanismo de crescimento em todas as suas fases.

\section{A expansão das multinacionais}

Os dados disponíveis demonstram que a penetração das multinacionais é maciça e economicamente abrangente. As multinacionais cresceram mais rapidamente que o resto da economia durante o boom, e parecem ter mantido sua posição em anos recentes. Seu poder é potencializado pelo seu caráter oligopólico e pela sua superioridade tecnológica. O relatório da comissão de Inquérito sobre Multinacionais do Senado dos Estados Unidos (1975) demonstra que "com quase metade da indústria sob controle estrangeiro, o comportamento das multinacionais é um determinante crítico da performance da economia brasileira. Além do mais, como muitas firmas estrangeiras são oligopolistas, a desnacionalização está ligada à concentração do mercado de produtos. Concentração de mercado confere poderes adicionais às multinacionais, liberadas da disciplina imposta pela competição" (Newfarmer e Muller, 1975).

O peso da capital local diminui em comparação ao das empresas estatais e multinacionais, tanto em termos de tamanho das empresas como da proporção de participação no patrimônio total. De 1966 a 1972, o número de indústrias privadas brasileiras constante da lista das 300 firmas mais importantes (de acordo com a magnitude do capital) caiu de 156 para 139. O capital das companhias brasileiras incluídas na lista das 300 caiu de 36\% em 1966 para 28\% em 1972. Nada indica que essa tendência tenha sido invertida após 1972. Na realidade, tanto as companhias estatais quanto as multinacionais mantiveram altas taxas de investimentos através da década. Um relatório do Ministério do Planejamento revela que entre 1970 e 1977 o capital dos empreendimentos públicos como um todo aumentou de $47.5 \%$ para $53.3 \%$ do total de uma amostra de 1069 firmas. A média anual dos investimentos multinacionais quase triplicou de 1969-1973 a 1974-1978 (Relatório do Banco Central).

Ninguém discute o impacto positivo das multinacionais do ângulo da industrialização brasileira. Mas o impacto global do capital estrangeiro é avaliado de maneiras muito diversas. A burguesia local sempre foi favorável a investimentos estrangeiros diretos no país, como um 
modo de incorporação de tecnologia avançada. Pesquisas empíricas não detectaram nenhum componente nacionalista significativo na ideologia empresarial local (Cardoso, 1972; Diniz e Boschi, 1978). Entretanto, muitas vozes, dentro e fora dos aparelhos de Estado, clamam por um controle mais efetivo sobre as multinacionais no país, e por negociações mais duras com elas. A oposição popular denuncia os altos custos sociais do desenvolvimento, e chama a atenção para a alienação cultural e econômica do país. Mas as esperanças baseadas na ação política de uma burguesia nacional progressista parecem ter desaparecido.

\section{Industrialização e relações internacionais}

A estrutura da Balança de Pagamentos brasileira alterou-se profundamente nos últimos 15 anos. Durante esse período, a integração da economia local ao sistema capitalista internacional foi fortemente encorajada por todos os governos desde 1964.

A expansão súbita do comércio externo em 1969/1973 - quebrando uma tradição de baixas cifras nessa coluna - é claramente a mudança mais significativa desse período. Ela reflete tanto o aumento do poder industrial brasileiro quanto uma tentativa deliberada por parte das autoridades de encorajar o comércio com vistas ao desenvolvimento. Entretanto, o equilíbrio da balança comercial acompanhado de uma acentuação dos déficits de serviço requerem recursos extras de capital. Condições extremamente favoráveis foram criados no país para o financiamento externo, que jorrava no país principalmente sob a forma de empréstimos em moeda contraídos por firmas públicas e privadas. A magnitude bruta desse fluxo indica que o equilíbrio das transações correntes não era a única explicação, e talvez nem mesmo a explicação mais importante da política de endividamento externo iniciado em 1969/1973. Recursos externos alimentavam o sistema financeiro interno e aumentavam, ao mesmo tempo, as reservas de moeda estrangeira do Banco Central, abrindo caminho para ousadas políticas de expansão posteriores.

Essas tendências persistiram no período 1974/1978, e tendências novas apareceram. Um déficit substancial na balança comercial foi causado pela tentativa deliberada do Governo de não compensar os vertiginosos aumentos do custo do petróleo pelo corte de outras importações, especialmente de bens de capital. Bens manufaturados e semi-manufaturados representavam no período $46 \%$ das exportações totais, contra $26 \%$ no período anterior. Apesar desse desempenho, cifras elevadas de importação, 
combinadas com uma elevação negativa dos serviços, geraram um enorme déficit de transações correntes. $\mathrm{O}$ balanço total permaneceu positivo, graças à entrada verdadeiramente maciça de recursos externos, novamente absorvida principalmente por firmas públicas e privadas. A relação entre rendas de capital e amortizações sobre exportações caiu um pouco em 1974/1978; mas, obviamente, tensões futuras estavam sendo geradas. Os efeitos dolorosos da carga financeira logo se fariam sentir. A dívida externa total saltou de cerca de 12 bilhões de dólares em dezembro de 1973 para 43 bilhões em 1978 e para perto de 60 bilhões em 1980.

A dependência tecnológica aprofundou-se durante todo esse

Tabela 3: Balanço de Pagamentos (US\$ milhões - Médias anuais)

\begin{tabular}{|c|c|c|c|}
\hline $\begin{array}{l}\text { Transações correntes e de } \\
\text { capital (exceto empréstimos } \\
\text { Compensatórios) }\end{array}$ & $1965 / 1968$ & $1969 / 1973$ & $1974 / 1978$ \\
\hline Balança Comercial & 333 & -5 & -2.248 \\
\hline Exportações & 1.718 & 3.629 & 10.304 \\
\hline \multicolumn{4}{|l|}{$\begin{array}{l}\text { Dos quais: } \\
\text { - bens manufaturados e }\end{array}$} \\
\hline Semi-manufaturados & 430 & 957 & 4.323 \\
\hline \multicolumn{3}{|l|}{ Das quais: } & - 12.552 \\
\hline - bens de capital & -482 & -1.347 & -3.440 \\
\hline - petróleo e sub-produtos & -124 & -427 & -3.470 \\
\hline \multicolumn{4}{|l|}{ Dos quais: } \\
\hline - lucros e dividendos & -54 & -136 & -376 \\
\hline - juros & -160 & -318 & -1.729 \\
\hline - royalties e outros & -107 & -65 & -249 \\
\hline \multicolumn{4}{|l|}{$\begin{array}{l}\text { Transações Correntes (Líquido) } \\
\text { (incluindo operações sem }\end{array}$} \\
\hline Contrapartida) & -81 & -1.066 & -5.961 \\
\hline Operações de Capital (Líquido) & $146(1)$ & 2.147 & 6.748 \\
\hline Entradas (1) & 645 & 3.899 & 10.770 \\
\hline \multicolumn{4}{|l|}{ Das quais: } \\
\hline - investimentos & 66 & 401 & 1.099 \\
\hline $\begin{array}{l}\text { - empréstimos e financiamentos } \\
\text { (mais de } 360 \text { dias) }\end{array}$ & 435 & 2.657 & 8.974 \\
\hline \multicolumn{4}{|l|}{ Dos quais: } \\
\hline Saídas & -499 & -1.752 & -4.022 \\
\hline Das quais: & & & \\
\hline - empréstimos e financiamentos & -267 & -978 & -3.280 \\
\hline
\end{tabular}

Fonte: Boletins mensais e relatórios anuais do Banco Central.

(1) - Médias anuais das operações de capital para 1964/1968 provêm do Relatório Anual de 1969 do Banco Central. 
período. Esse fenômeno não transparece suficientemente na balança de pagamentos porque o coeficiente das importações caiu em termos relativos. O coeficiente de importação no investimento total também parece ter caído (Relatório do BC, 1978). A produção interna de bens de capital cresceu mais rapidamente do que a oferta externa. Entretanto o problema do desenvolvimento tecnológico local parece ter-se agravado. Uma pesquisa recente levada a cabo por pesquisadores do Ministério do Planejamento entre produtores locais de bens de capital levou à conclusão de que "se a política industrial atual se mantiver, as perspectivas de desenvolvimento tecnológico na indústria de bens de capital nacional são desfavoráveis. A dependência tecnológica será agravada levando eventualmente à marginalização dos produtores nacionais no mercado e à desnacionalização crescente do setor". À medida que empresas locais diversificam e sofisticam suas linhas de produtos, a atualização de patentes estrangeiras torna-se mais e mais econômica do ponto de vista do produtor individual. O processo se autoperpetua. Também se observou que a forte dependência com respeito ao licenciamento torna o produto local vulnerável às pressões estrangeiras pela participação no capital. (Erber e outros, 1978).

\section{O campo e as cidades: o reverso da medalha}

Os efeitos desse estilo de industrialização no setor agrícola são complexos e ambíguos. Estimulados pelas políticas de taxação, preços mínimos e créditos subsidiados do Governo, as exportações primárias retomaram o fôlego. Nos setores afetados pelo boom de exportação, o uso de máquinas agrícolas e outros insumos modernizou os métodos de cultivo, principalmente nos estados mais ricos do Centro e Sul. A produção de culturas de subsistência (arroz, feijão, mandioca e batatas) foi substituída e cresceu pouco ou declinou na última década.

A capitalização das propriedades médias e grandes nas regiões Sul e Central implicou a extensão da legislação trabalhista às áreas rurais. Isso foi feito indiscriminadamente desde o início dos anos 60 . Em conseqüência os colonos foram expulsos das fazendas. Destes, parte emigrou para as cidades e parte permaneceu nas cidades pequenas, trabalhando a terra como assalariados temporários (bóias frias).

Os trabalhadores empregados estavelmente são relativamente poucos. Eles trabalham nas grandes fazendas, realizando uma série de serviços na entressafra. Embora o número de bóias frias e assalariados permanentes tenham aumentado, a unidade familiar (pequenos proprietários e 
Tabela 4: Crescimento anual médio na produção agrícola.

\begin{tabular}{lccc}
\hline Produtos & $1950 / 59$ & $1960 / 69$ & $1967 / 78$ \\
\hline Arroz & 3.61 & 3.23 & 3.21 \\
Feijão & 2.92 & 4.19 & -1.60 \\
Mandioca & 3.33 & 6.07 & -1.63 \\
Batatas & 4.84 & 4.34 & 1.73 \\
Cebolas & 5.63 & 3.48 & 5.91 \\
Milho & 3.30 & 4.75 & 2.47 \\
Trigo & 3.48 & 5.89 & 10.64 \\
Soja & 8.18 & 16.39 & 29.78 \\
Café & 6.62 & -6.94 & -3.91 \\
Cana-de-Açúcar & 5.42 & 3.63 & 5.69 \\
Algodão & 1.31 & 1.61 & -2.30 \\
Laranja & 3.02 & 6.02 & 11.88 \\
\hline
\end{tabular}

Fonte: Homem de Mello, F. B.. A Política Econômica e o Setor Agrícola no PósGuerra.

parceiros) ainda predomina no país.

A maioria dessas unidades familiares são minifúndios, que têm um papel importante na economia brasileira. Eles contêm culturas de sobrevivência para as famílias de trabalhadores rurais; geram excedentes comercializáveis de bens de primeira necessidade a preços muito baixos e abrigam uma reserva de força de trabalho passível de mobilização para os latifúndios vizinhos na época do plantio e da colheita (Sá Jr.,1972; Oliveira, 1973).

A capitalização da agricultura ocorreu apenas em algumas poucas áreas próximas de centros industriais. Com exceção desse fenômeno, a economia rural não foi afetada substancialmente pela industrialização. A renda monetária dos assalariados rurais é apenas $60 \%$ do salário mínimo oficial do Rio de Janeiro (Bacha, 1976). A política local ainda se baseia no clientelismo local. Essas estruturas têm sido funcionais para o desenvolvimento brasileiro (Paiva, 1966). A baixa produtividade da maioria das culturas é compensada por mão-de-obra extremamente barata o que se torna possível pela persistência de ampla agricultura de subsistência. A estabilidade a longo prazo dos preços setoriais relativos beneficia o setor industrial, onde a produtividade cresce rapidamente (Silva, 1977).

Já que não existem pressões fortes para a capitalização da terra, e já que o binômio minifúndio-latifúndio tem sido um fator de estabilidade política no campo, as estruturas de economia rural persistem. O crédito público, as políticas fiscais e de reforma agrária (distribuição de terras) beneficiam os grandes proprietários e negligenciam os pequenos, con- 
tribuindo portanto para a manutenção do status-quo.

Uma situação global desta natureza gera tensões crescentes à medida que a economia se desenvolve. Em primeiro lugar, as tensões sociais nas cidades se agravam pelo fluxo migratório e a falta de trabalho nas indústrias. Em segundo lugar, a especulação imobiliária aumenta à medida em que a fronteira agrícola se expande. Sérios conflitos se multiplicam por todo o país entre os posseiros e os agentes dos grupos econômicos invasores.

As cidades resumem o país. Trabalhadores industriais, empregados domésticos, desempregados, semi-empregados, todos eles fazem parte de uma imensa, sempre crescente massa de pessoas dentro e ao redor das cidades. Eles não constituem grupos sociais em transição, como pretendem alguns. Expressam a peculiar combinação de condições pré-capitalistas e de condições capitalistas altamente desenvolvidas na formação histórica brasileira. Nesse tipo de formação, a mobilidade social vertical é ilusória: a pobreza urbana nada mais é do que a reciclagem da indigência rural.

A taxa ponderada de desemprego nas quatro maiores cidades industrias do Brasil (São Paulo, Rio de Janeiro, Belo Horizonte e Porto Alegre) era de 6.4\% em maio de 1980, para a população acima de 15 anos. A taxa de semi-empregados - os que trabalham menos do que as horas regulamentares por semana ou os que ganham menos do que um salário mínimo por mês - é mais ou menos a mesma (IBGE). A população das áreas urbanas de São Paulo e do Rio de Janeiro tem aumentado a uma taxa de $4.5 \%$ anualmente na última década. A população total aumentou cerca de $2.9 \%$ no mesmo período. O crescimento do mercado de trabalho no país foi de $7.3 \%$ em média em $72-73$ e $2.3 \%$ de 74 a 79 (IBGE). Essas cifras sugerem uma tendência de expansão do "setor marginal" sempre que o crescimento industrial seja menos que $7-8 \%$ por ano.

\section{O “modelo brasileiro" - uma avaliação de conjunto}

O desenvolvimento é no Brasil a manifestação e a conseqüência da internacionalização da economia. Os três aspectos principais da internacionalização são os seguintes: primeiramente, a internalização do capital estrangeiro. As multinacionais integram o sistema produtivo local, definido por complementaridades técnicas e econômicas e produzem principalmente para o mercado interno. Em segundo lugar, a economia brasileira tem um papel específico na divisão internacional do trabalho: ela é exportadora de bens manufaturados baratos e importadora de equipamento e tecnologia avançados. Finalmente, a realização de uma crescente proporção 
de lucros gerados localmente depende da sua conversão em meios de pagamento internacionais. (Oliveira, F., 1977). É portanto essencial uma expansão contínua das exportações e dos financiamentos externos.

Esse modelo difere do modelo exportador tradicional. As exportações são agora diversificadas e instrumentais para a acumulação local e para a realização dos lucros. Ele também difere do modelo das "economias centrais", tanto no sentido de um país imperialista quanto no sentido Cepalino de uma economia totalmente industrializada, estruturalmente diversificada e integrada. O Brasil é uma economia industrializada na qual os meios estratégicos de produção - tecnologia e petróleo - são produzidos externamente, e cuja indústria não é suficientemente competitiva para incorporar esses insumos sem sérias tensões sócio-econômicas e instabilidade cíclica.

A internacionalização da economia brasileira não implicou em estagnação econômica. Pelo contrário, essa foi a forma que assumiu a rápida acumulação de capital no país. Também não é certo que esse fenômeno tenha levado à completa submissão às multinacionais ou a governos estrangeiros. Operou aí um tipo de dialética: a internacionalização acompanhou-se do fortalecimento de interesses locais (senão nacionais). A análise das tendências mais recentes, realizada na última seção, sugere a possibilidade de alteração desse processo.

Historicamente, no Brasil, uma estrutura industrial moderna diversificada ligou-se a um mercado interno previamente em expansão. Essa formação particular tornou-se um sistema (relativamente) independente e competitivo no contexto internacional. Á medida em que os interesses internacionais no país cresceram, e a economia local se tornou mais e mais integrada à economia internacional, a margem de pressões arbitrárias por parte de interesses estrangeiros diminui. Perguntando há algum tempo atrás, sobre a dívida externa, um ministro do atual governo sorriu: "Deveríamos nos preocupar se devêssemos pouco. Como devemos muito, os credores é que devem preocupar-se".

No contexto do capitalismo selvagem brasileiro, o Estado tende a desligar-se de interesses excessivamente particulares. Isso não se deve às virtudes cívicas das autoridades. A autonomia relativa do Estado é reforçada pela impossibilidade de atender às demandas de todos. A luta entre corporações pelos favores do Estado é selvagem. Os conflitos urbanos e industriais são agudos. Nesse contexto, um Estado forte e relativamente independente é a contrapartida, não de uma "sociedade frouxamente organizada", mas de uma sociedade extremamente competitiva. O Estado brasileiro não é um simples serviçal deste ou daquele grupo específico. Ele é o ful- 
cro de uma ordem normativa que reflete, através de mediações ideológicas complexas, os interesses a longo prazo das classes dominantes como um todo.

\section{O "MILAGRE BRASILEIRO"}

De 1964 a 1966 ocorreu no país um processo de seleção natural, com um "pequeno empurrão" das políticas de austeridade do Governo. $\mathrm{O}$ crédito ao setor privado declinou em termos reais. $\mathrm{O}$ equilíbrio orçamentário foi restabelecido. O capital "em excesso" foi eliminado. Muitas firmas de pequeno e médio porte faliram, muitas foram incorporadas por firmas maiores. O número de novas filiais de multinacionais formadas pela aquisição de firmas locais cresceu de 24 (1945-1965) para 30 (1966-1972), enquanto que o número de novas firmas inauguradas caiu de 89 para 29 nos mesmos períodos. Paralelamente começa a funcionar a "imaginação reformista" do Governo. Um impressionante elenco de medidas prepara o "milagre":

- uma política de arrocho salarial reforçou o processo natural da concentração da renda e da propriedade. Essa política foi implementada à força. Greves foram praticamente proibidas, 425 sindicatos sofreram intervenção, a militância sindical foi reprimida. Os salários mínimos foram fixados substancialmente abaixo dos níveis de inflação;

- as exportações foram encorajadas por uma imensa bateria de incentivos fiscais, creditícios e cambiais. Como resultado, os exportadores de produtos manufaturados receberam subsídios importantes que lhes permitiram colocar os seus produtos no exterior, por um preço FOB 40 a $60 \%$ mais barato que o preço doméstico. Posteriormente a produção para exportação foi também acelerada por incentivos substanciais tais como isenção do imposto sobre a renda, as remessas de lucro e sobre certas importações. Benefícios fiscais e creditícios foram estendidos também a firmas exportadoras (Doellinger e outros, 1974);

- o sistema financeiro foi drasticamente reformado. A inovação básica foi a correção monetária dos ativos não monetários (depósitos a longo prazo, letra de câmbio, títulos da dívida pública e cadernetas de poupança). Protegida contra a inflação 
a poupança voluntária cresceu rapidamente e foi canalizada para a indústria de construção e crédito ao consumidor. A poupança institucional forçada também foi aumentada pela criação de grandes fundos sociais, financiados por deduções sobre salários na fonte;

- o sistema fiscal também foi reformado com vistas a aumentar os rendimentos federais;

- subsídios de serviços públicos foram eliminados, preparando o caminho para a expansão das indústrias de equipamentos elétricos e de construção civil associados a um vasto programa energético.

Estimulada por essas medidas e por condições favoráveis, a indústria expandiu-se com rapidez. Já em 1965-1967 o setor de bens de consumo durável começava a mover-se. De 1967 a 1970, as indústrias automobilísticas e de bens de capital cresceram à taxa de $23.9 \%$ e $13.7 \%$ por ano respectivamente. Segundo as estimativas da FINEP, para o subperíodo 1971-1973 as taxas médias foram de $21.2 \%$ para os duráveis e de $39.0 \%$ para os bens de capital. A taxa de crescimento para o conjunto da indústria de transformação foi de $13.3 \%$ anualmente no período 1967 a 1973. A inflação caiu de 40\% em 1966 a 15.5\% em 1972-1973, de acordo com os dados oficiais.

Uma comparação com a fase de expansão anterior (1957-1961) permite esclarecer melhor certos aspectos do "milagre". Durante o período Kubitschek, os investimentos estrangeiros concentravam-se em produtos novos, particularmente no setor de bens de capital. A estrutura industrial foi substancialmente alterada. O impacto desses investimentos na taxa global de produtividade foi tão acentuado que todos os extratos de renda moveram-se para cima em termos reais. A balança comercial e o setor primário não foram afetados pelo dinamismo industrial. A ausência de um mercado financeiro digno desse nome levou o governo a financiar os seus investimentos por via de poupança institucional forçada e de déficits orçamentários. Os recursos financeiros externos eram modestos.

No final dos anos 60, os bens duráveis (automóveis e eletrodomésticos) e a construção civil tomaram a liderança, valendo-se inicialmente da capacidade ociosa existente. A estrutura não se transformou radicalmente. Baixos salários e concentração de renda incorporaram-se aos objetivos da política econômica. Criou-se um mercado financeiro, captando poupanças voluntárias no país e recursos baratos no exterior.

O Estado fortaleceu sua capacidade de controle dos fluxos de 
Tabela 5: Produção industrial por setores

Taxas médias anuais de crescimento, 1949-1977

\begin{tabular}{cccccc}
\hline Períodos & $\begin{array}{c}\text { Bens de } \\
\text { Capital }\end{array}$ & $\begin{array}{c}\text { Bens de } \\
\text { Consumo } \\
\text { Durável }\end{array}$ & $\begin{array}{c}\text { Bens de } \\
\text { Consumo } \\
\text { não durável }\end{array}$ & $\begin{array}{c}\text { Bens } \\
\text { Intermediário }\end{array}$ & Total \\
\hline $1949-1955$ & 11.0 & 17.1 & 6.7 & 11.8 & 8.8 \\
$1955-1962$ & 27.0 & 24.0 & 6.6 & 12.1 & 11.3 \\
$1962-1967$ & -2.6 & 4.1 & 0.0 & 6.3 & 2.7 \\
$1967-1973$ & 18.1 & 23.6 & 9 & 13.5 & 13.3 \\
$1973-1977$ & 8.4 & 5.5 & & 8.7 & 6.6 \\
\hline
\end{tabular}

Fonte: Reichstul e Goldenstein, 1980.

Tabela 6: Formação Bruta de Capital no Setor Privado e Empresas Públicas Taxas anuais de crescimento, 1975-1978.

\begin{tabular}{ccc}
\hline Anos & $\begin{array}{c}\text { Setor } \\
\text { Privado }\end{array}$ & $\begin{array}{c}\text { Empresas } \\
\text { Públicas }\end{array}$ \\
\hline 1975 & 5.3 & 18.0 \\
1976 & 5.7 & 9.7 \\
1977 & 1.5 & 15.0 \\
1978 & 4.0 & 10.5
\end{tabular}

Fonte: Reichstul e Coutinho, 1980.

investimentos através do controle do sistema financeiro e de fases estratégicas do processo produtivo. Os setores públicos e privados tornaram-se mais integrados; mais e mais o Estado dispunha-se a cobrir os riscos dos grandes investidores. A economia voava mais alto que nunca, e começava a faltar-lhe o ar.

Abriu-se um hiato entre a acumulação e a demanda. A indústria de bens duráveis, incapaz de manter sua formidável expansão, baqueou primeiro e sofreu mais. O setor de bens de capital resistiu mais tempo, graças aos investimentos públicos. Mas sua taxa de investimento também caiu (Tavares e Belluzzo, 1979).

De 1974 até o presente, os investimentos públicos cresceram a taxas mais elevadas que os privados. Isso ocorreu até mesmo em 1976, quando o governo tentou deter a inflação e melhorar sua posição devedora interna e externa. Mas altas taxas de investimentos públicos produziam ten- 
sões financeiras consideráveis. As empresas estatais foram estimuladas a buscar recursos no mercado de euro-dólares, e os projetos estatais prosseguiram.

Desde meados dos 70 os economistas têm alertado para as crescentes dificuldades da economia. Muitos já falavam desde então em crise, no entanto, o PND continuou crescendo a uma taxa de 6 a $7 \%$ ao ano de 1974 a 1980. Por essa razão, o fato das análises econômicas deslocou-se do tema do crescimento global para o que poderia chamar-se o "paradoxo do crescimento em recessão". Com efeito, a crise no Brasil é única em vários aspectos.

Após o impressionante boom de investimentos no triênio do "milagre", tudo indicava que a indústria amadurecera para a recessão. A posição de conjunto foi agravada pelo fato de que o super-aquecimento coincidiu com a elevação dos preços do petróleo e com o arrefecimento econômico mundial. As taxas de crescimentos setoriais caíram; mas não a ponto de caracterizar uma recessão. Não se registraram falências em número alarmante. É verdade que a inflação começou a acelerar-se, mas o orçamento federal manteve-se em equilíbrio, os salários permaneceram sob controle e o cruzeiro.

Os efeitos dinâmicos dos investimentos públicos, já mencionados, foram parcialmente neutralizados por importantes fatores depressivos, como sejam a grande capacidade ociosa, a escalada dos preços do petróleo, a juventude de parte substancial do equipamento industrial e o alto nível de endividamento dos consumidores. Os recentes desenvolvimentos da economia brasileira podem ser descritos em termos da interação desses fatores opostos.

Numa estrutura industrial oligopolística, a falta de oportunidades de investimentos libera recursos financeiros. Ainda que reduzidos, os lucros da atividade produtiva são maiores que as necessidades de investimentos, dadas as expectativas de demanda. Tais excedentes financeiros ingressam no sistema financeiro e são parcialmente absorvidos pelos projetos estatais de investimentos. Naturalmente, isso torna-se possível mediante generosas correções monetárias e juros adequados. Tal mercado, como se vê, é um convite irresistível à especulação. Daí decorrem três conseqüências. Primeiramente, a especulação e o investimento entram em competição; mecanismos financeiros, concebidos para estimular a produção gradualmente transformam-se em obstáculos à recuperação econômica. Em segundo lugar, os retornos das grandes companhias contêm agora um componente monetário importante, e a interdependência entre o Estado e os interesses privados torna-se mais complexa e profunda. Em ter- 
ceiro lugar, os recursos públicos tornam-se escassos. A dívida interna, aumentada por correções monetárias, subsídios e juros a pagar, absorve uma proporção cada vez maior dos recursos estatais.

Para tocar as coisas há que recorrer a financiamentos externos. Enormes empréstimos em moeda são contraídos por empresas públicas e privadas. Esse é um dos principais fatores explicativos da magnitude extraordinária da dívida externa. O custo total do dinheiro sobe, e uma proporção crescente do PNB é apropriada pelo setor financeiro.

Esses mecanismos aceleram a inflação. O impacto da despesa governamental sobre os preços é aparente não tanto no orçamento fiscal, como no orçamento monetário. Note-se que para as firmas, semelhante ciranda é fator de elevação de custos. A partir desse ponto, a inflação já não é facilmente controlável e o marking up (sobre os custos de produção) pelas firmas oligopolísticas penaliza o setor competitivo e os consumidores, garantindo ao mesmo tempo gordos retornos às grandes companhias.

$\mathrm{Na}$ raiz dos processos descritos descobre-se uma barganha tácita entre o governo e o grande capital. O governo pede às grandes empresas e credores externos que não repatriem capital e lucros, que não abandonem planos de investimentos, que não sejam intransigentes nos termos dos financiamentos, que não demitam muitos trabalhadores, que não se impacientem demais com a inflação, que não retirem a confiança no governo. Em troca, o governo assegura a reprodução do capital-moeda até que soluções reais sejam encontradas e um novo período de expansão tenha início.

\section{PERSPECTIVAS}

Embora isso possa parecer inconcebível a muitos economistas, o combate à inflação - que já ultrapassou os $100 \%$-- não é a meta prioritária do governo. A ênfase recai na sustentação da taxa de investimento e a esse objetivo se subordinam os esforços múltiplos de captação de recursos internos e externos. É possível que semelhante obsessão desenvolvimentista seja inerente ao próprio regime, cuja justificativa histórica fundamental é a construção de uma Grande Potência. No entanto, tal não é a linguagem do momento. Hoje em dia, trata-se prioritariamente de evitar a recessão; em nome dessa causa, o governo amplia sua margem de manobra na área econômica e procura convencer os vários setores sociais de que sua política é a única possível.

Pelos padrões brasileiros, a economia correu livre nos últimos 
anos, como se as dívidas interna e externa pudessem crescer indefinidamente contanto que o produto crescesse. Os ganhos especulativos dos setores industrial e financeiro podiam ser realizados a qualquer momento no mercado cambial. Dessa forma, o vínculo crucial entre dívida interna e externa acelerava a espiral monetária. Mas as taxas de juros cresciam com os riscos crescentes em todos os mercados. $\mathrm{O}$ dinheiro do governo reduziu-se e, mais que isso, reduziu-se o poder de controle governamental sobre a economia. A "confiança" no governo - medida em termos de investimentos privados e empréstimos - tornou-se cada vez mais cara.

A partir do "pacote" de dezembro de 1979, uma série de medidas vigorosas foram tomadas para reverter a situação. Em primeiro lugar, o governo procurou enquadrar o sistema financeiro. As taxas de juros foram regulamentadas mais estritamente e reduzidas. Foram anunciadas por antecipação os tetos para correção monetária e empréstimos globais referentes a 1980; esses tetos seriam inferiores à taxa prevista de inflação. As importações foram submetidas ao imposto sobre operações financeiras, e as alíquotas do imposto de renda sobre os extratos mais altos foi elevada. Em segundo lugar, reforçaram-se os controles sobre os preços. Em terceiro lugar, foram eliminados subsídios às exportações e decretada uma maxi-desvalorização do cruzeiro de $30 \%$. Finalmente, adotou-se uma política de liberação dos serviços públicos. Essas duas últimas medidas, admitiu-se, provocariam uma "inflação corretiva": seu impacto inflacionário a curto prazo seria compensado favoravelmente no médio prazo por efeitos benéficos sobre a posição financeira do governo e sobre o balanço de pagamentos.

As primeiras estimativas indicam que esse conjunto de medidas eleva de 3 a $4 \%$ a apropriação pública do PNB. No entender de alguns analistas, circunstâncias externas, a pressão dos grupos de interesses bem cedo atenuaram ou neutralizaram seus efeitos. Convém assinalar, todavia, que, recusando-se os grupos mais fortes a abrir mão da sua fatia - na verdade, todos sentem-se lesados uns face aos outros nesse tipo de situação - o peso do combate à recessão recai sobre as massas populares. Os serviços públicos têm sido reajustados segundo taxas bastante superiores às da inflação; os salários do funcionalismo público foram drasticamente cortados; e os lucros têm sido protegidos mediante um forte arrocho salarial sobre os extratos médios de salários.

Todos concordam que o governo está numa encruzilhada. Um dos caminhos leva a um controle estatal ainda maior da economia como um todo. Nesse cenário, os componentes de curto prazo das dívidas interna e externa são renegociados, com prejuízos maiores ou menores para os 
vários credores. São introduzidos certos controles das margens de lucros dos oligopólios, o sistema financeiro é nacionalizado na prática, senão no papel. Os salários são estritamente controlados e a proporção dos investimentos públicos sobre o total aumenta.

O outro caminho leva a políticas convencionais de austeridade. Tal é, em essência, a proposta do Fundo Monetário Internacional, em recente estudo preparado para o governo brasileiro, embora os termos usados não fossem brutais como em outros tempos. Nesse cenário, a idéia básica é restabelecer-se o mercado como mecanismo capaz de melhor orientar a alocação de recursos. Em particular, as taxas de juros são liberadas e índices financeiros mais seguros são adotados. Eliminam-se subsídios às exportações e a indexação oficial dos salários. Corta-se o gasto público, afrouxa-se o controle cambial. Desemprego, redução salarial, falências, taxas negativas de crescimento, etc. - tudo isso é visto como males necessários na rota da salvação econômica por meio da livre empresa.

O primeiro cenário deixa os empresários nervosos. Eles não questionam o "modelo": o Estado tem feito um bom trabalho. Mas em definitivo eles temem um Estado ainda mais poderoso e autônomo. De modo particular, o empresariado vê com maus olhos e alguma ganância o constante crescimento das empresas estatais. Por outro lado, todos sabem, mesmo os capitais mais poderosos, que um tratamento depressivo teria conseqüências imprevisíveis, tanto econômicas quanto políticas. Tanto a crise internacional quanto a estrutura oligopolística da economia brasileira reduziriam a eficiência da terapia convencional, agravariam a recessão e dificultariam a retomada.

Não há saída aparente para esse dilema. Uma solução híbrida será provavelmente tentada. Os investimentos públicos serão cortados em parte, mantendo-se os programas de energia (álcool, hidroelétricos, energia nuclear). O crédito interno deve ser reduzido. A dívida externa - que pouco a pouco se transforma no principal ponto de estrangulamento de todo o sistema - crescerá bastante menos do que no passado. A recessão parece inevitável. Resta saber quão profunda e quão longa será. A única previsão fácil nesse quadro diz respeito a uma tendência que já é visível: os trabalhadores, e em particular, neste estágio do processo, amplos setores de colarinhos brancos serão convidados a pagar a conta.

É preciso notar enfim, que a presente equipe governamental não tem uma estratégia definida de desenvolvimento. Por ora, ao que parece, trata-se de manter o barco à flor d'água. A menos que se tomem as exortações publicitárias - "poupem e exportem" - como tal estratégia. Mas isso 
não convence, pois não se sabe bem como fazer isso. Melhor será reconhecer que qualquer diretriz inovadora na economia implica rever o próprio modelo em seu arcabouço, e implica sobretudo a instituição de controles democráticos sobre os lucros abusivos, as especulações financeiras, as negociatas, as mordomias, as contas no exterior: quaisquer que sejam os rumos alternativos, - as opções de investimentos, amplitude e funções da política social, por exemplo, - não se concebe que não se definam por ampla consulta ao povo.

Todavia, não há que se iludir: o capitalismo no Brasil está vivo, e conspira o futuro por vias que as circunstâncias lhe abrem. Uma primeira linha de ataque será talvez a capitalização do setor primário tanto na agricultura como na mineração, com forte participação das corporações multinacionais. O projeto Metal Amazônia é um projeto abrangendo investimentos no valor de 30 bilhões de dólares: (a) na exploração das jazidas de ferro, cobre, alumínio, manganês e ouro da região de Carajás; (b) no desenvolvimento de uma grande siderúrgica no local; (c) na implantação de projetos agrícolas e pecuários cobrindo uma área de 7 milhões de hectares; (d) na criação de novas redes viárias e ferroviárias, bem como de um porto em São Luiz do Maranhão. Capitais multinacionais negociam sua fatia do bolo, levando em conta, naturalmente, a delicada situação do Brasil como grande devedor de dólares. Uma segunda linha de ataque será a participação nos programas de energia, armamentos e de integração nacional (estradas e comunicações) que corporificam a estratégia de poder do complexo industrial militar. Possivelmente, e apesar de tudo, uma frente será a indústria automobilística. Os imensos interesses do setor pensam tirar proveito da "racionalização" do mercado mundial, consolidando o país como centro produtor. Isso não parece uma simples fantasia: a Volkswagen deve exportar 120.000 veículos em 1980, segundo previsões da própria companhia. Enfim, abre-se a possibilidade de explorar melhor as relações comerciais com a América Latina, África e países socialistas. Na América Latina, e em particular no Cone Sul, duas circunstâncias podem justificar tais expectativas: a agressividade da economia brasileira e o liberalismo econômico dos regimes militares nos países vizinhos.

Talvez seja legítimo concluir que, face ao emperramento dos mecanismos econômicos que têm sustentado o crescimento nos últimos anos (concentração de renda, endividamento interno e externo etc.), desenha-se uma nova etapa em que fatores externos ao sistema passem a preponderar. Por fatores externos poderemos entender: (a) tanto o domínio por outros países de estágios cruciais e não internalizáveis do processo 
produtivo que se completa no Brasil - petróleo, tecnologia, por exemplo (b) como decisões de investimento que não têm qualquer relação com o mercado interno de consumo, decorrendo, antes, de estratégias inteiramente multinacionais. Segue-se o aumento da taxa de exportação do excedente produzido no país e o gradual esgotamento do patrimônio natural. Um governo que deve o que deve no exterior e que se nega a ser o governo de todos os brasileiros não teria recursos (econômicos ou políticos) nem razões de peso para contrapor-se às tendências descritas.

Claro está que o capitalismo não se desenvolverá num vácuo político. Não é necessário, neste passo, muito realismo para prever-se tensões agudas no curso dos próximos anos: mas essa previsão não se baseia tanto nos problemas da economia - visto que não se justificam, empírica ou teoricamente, passagens imediatas de um plano a outro - como na constatação de que, ocorrendo tais problemas, o sistema político não se tem mostrado capaz de absorvê-los e solucioná-los em termos nacionais.

\section{REFERÊNCIAS BIBLIOGRÁFICAS}

ANDRADE, Regis de Castro. "Perspectivas sobre o estudo do populismo no Brasil". Encontros com a Civilização Brasileira n.o 7, 1978.

BACHA, Edmar. Os Mitos de Uma Década. Rio de Janeiro. Paz e Terra, 1976.

BELLUZZO, Luiz Gonzaga M. e CARDOSO DE MELLO, João Manuel. "Reflexões sobre a crise atual". Escrita Ensaio n. 2, São Paulo, 1977.

CARDOSO, Fernando Henrique. Empresário industrial e desenvolvimento econômico no Brasil. São Paulo. Difel, 1972.

Departamento Intersindical de Estatística e Estudos Sócio-Econômicos (DIEESE) - Salário Mínimo. Revista DIEESE, Abril, 1979.

DINIZ, Eli \& BOSCHI, Renato R.. Empresário Nacional e Estado no Brasil. Rio de Janeiro. Forense Universitária, 1978.

DOELLINGER, Carlos von; CASTRO, Hugo B. de, e CAVALCANTE, Leonardo C.. A política brasileira de comércio exterior e seus efeitos. IPEA, Relatório de Pesquisa n.o 22, 1974.

ERBER, F. S.; TAVARES Jr., J.; ALVES, S. F.; REIS, I. G. \& REDIRGER, M. L.. Absorção e criação de tecnologia na indústria de bens de capital. Financiadora de Estudos e Projetos (FINEP), Série Pesquisas n. 2, Rio de Janeiro, Março, 1974.

Economic Comission for Latin America (ECLA). Basic Equipment in Brasil. (The Manufacture of Industrial Machinery and Equipment in Latin America, vol. 1). New York, 1963.

Escritório de Pesquisa Econômica Aplicada (EPEA). Situação monetária, creditícia e do mercado de capitais. Plano Decenal de Desenvolvimento Econômico e Social, 1966.

FISHLOW, Albert. "Algumas Reflexões sobre a Política Econômica Brasileira após 1964". Estudos CEBRAP n.o 4, janeiro-março, 1974.

FURTADO, Celso. Formação Econômica do Brasil. São Paulo. Companhia Editora Nacional, 
1968.

KAHIL, Raouf. Inflation and Economic Development in Brasil, 1946-1963. Oxford. Clarendon Press, 1973.

LEFF, Nathaniel H. The Brazilian Capital Goods Industry, 1929-1964. Harvard University Press, 1968.

LESSA, Carlos. "Fifteen Years of Economic Policy". Economic Bulletin for Latin America, Vol. IX, n. 2, Novembro, 1964.

MARTINS, Luciano. Pouvoir et Développement Economique. Paris. Anthropos, 1976.

NEWFARMER, R. S. \& MUELLER, Willard. Multinational Corporations in Brazil and Mexico. (Report to the Subcommittee on Multinational Corporations, U. S. Senate), Washington, agosto, 1975.

OLIVEIRA, Francisco de. A economia da dependência imperfeita. Rio de Janeiro. Graal, 1977.

"A economia brasileira: crítica à razão dualista". Estudos CEBRAP n.o 2, 1972.

PAIVA, Ruy Miller. "Reflexões sobre as tendências de produção, da produtividade e dos preços no setor agrícola do Brasil". Revista Brasileira de Economia, junhosetembro, 1966.

REICHSTUL, Henri-Philippe e GOLDENSTEIN, Lidia. "Do complexo cafeeiro à industrialização". Gazeta Mercantil, Edição Especial, 29 de abril de 1980.

SÁ Jr., Francisco. "O desenvolvimento da agricultura nordestina e a função das atividades de subsistência". Estudos CEBRAP n.o 3, janeiro, 1973.

SILVA, Sérgio. Formas de acumulação e desenvolvimento do capitalismo no campo. São Paulo. Hucitec, 1977.

SINGER, Paul. "Ciclos de conjuntura em economias subdesenvolvidas". Revista Civilização Brasileira 1(2), maio, 1965.

SUZIGAN, Wilson. As empresas do Governo e o papel do Estado na economia brasileira. Aspectos da participação do governo na economia. Instituto de Planejamento Econômico e Social (IPEA), Monografia n. 26, 1976.

TAVARES Jr., José e DICK, Vera M.. "Governo, empresas multinacionais e empresas nacionais: o caso da indústria petroquímica". Pesquisa e Planejamento Econômico, dezembro, 1974.

TAVARES, Maria da Conceição. Acumulação de capital e industrialização no Brasil. Tese de Livre Docência, Faculdade de Economia e Administração, Rio de Janeiro, 1977. . e BELLUZZO, Luiz Gonzaga M.. "Notas sobre o processo de industrialização recente no Brasil". Revista de Administração de Empresas 19(1), janeiro-março, 1979. . e SERRA, José. Além da estagnação. Da substituição da importação ao capitalismo financeiro. Rio de Janeiro. Zahar, 1972.

e FAÇANHA, Luiz Otávio. "A presença de grandes empresas na estrutura industrial brasileira". Rio de Janeiro, dezembro, 1977 (mimeo).

WELLS, John. "Distribuição de rendimentos, crescimento e estrutura da demanda no Brasil na década de 60". in TOLIPAN, R. e TINELLI, A. C. (org.). A controvérsia sobre distribuição de renda e desenvolvimento. Rio de Janeiro. Zahar, 1975. 


\title{
RESUMOS/ABSTRACTS
}

\section{BRASIL: A ECONOMIA DO CAPITALISMO SELVAGEM}

\author{
RÉGIS DE CASTRO ANDRADE (1938-2002)
}

Originalmente publicado em 1981 na publicação que precedeu Lua Nova e no ano seguinte na Inglaterra (em Gienefel, M. e Godfrey, M., ed., The Struggle for Development - National Strategies in an International Context. London, Wiley), este artigo traça um retrato da economia brasileira da perspectiva do início dos anos 80. Analisa a formação e as características do "modelo brasileiro", examina o boom de 1968-1973 (o "milagre brasileiro") e assinala a emergência de uma nova etapa, em que fatores externos à economia nacional passariam a preponderar. Sustenta que o novo período seria marcado por tensões agudas, em parte porque o sistema político não seria capaz de assimilar os problemas econômicos.

Palavras-chave: Economia brasileira; economia e política no Brasil; capitalismo no Brasil.

\section{BRAZIL: THE ECONOMICS OF SAVAGE CAPITALISM}

Originally published in 1981, in the periodical preceding Lua Nova and in England the next year (in Gienefil, M. and Godfrey, M., ed., The Struggle for Development - National Stratregies in an International Context. London, Wiley), this article draws a picture of the Brazilian economy from de point of view of the early 80's. The construction and the features of the "brazilian model" as well as the boom of 1968-73 (the "brazilian miracle") are analyzed, and the emergence of a new stage with external factors at the forefront is pointed out. The author holds that the 
new period would be marked by acute tensions, partly due to the inability of the political system to tackle the economic problems.

Keywords: Brazilian economy; economy and politics in Brazil; capitalism in Brazil. 